\title{
Evaluation of a drowning prevention campaign in King County, Washington
}

\author{
Elizabeth Bennett, Peter Cummings, Linda Quan, Frances Marcus Lewis
}

\begin{abstract}
Objectives-A three year drowning prevention campaign focused on increasing the use of life vests among children 1-14 years old. An evaluation was conducted to determine campaign awareness, change in ownership and use of life vests by children, and predictors of life vest use. Setting-King County, Washington. Methods-Four telephone surveys were conducted with parents before, during, and after the campaign.

Results-The campaign was recalled by $50 \%$ of families surveyed. From before to after the campaign, reported life vest use by children on docks, beaches, or at pools increased from $20 \%$ to $29 \%(p<0.01)$ and life vest ownership for children increased from $69 \%$ to $75 \%(p=0.06)$. Among parents aware of the campaign, reported child life vest use increased from $20 \%$ to $34 \%$ $(\mathrm{p}<0.001)$ and ownership increased from $69 \%$ to $80 \% \quad(p<0.01)$. Among families unaware of the campaign, neither life vest use nor ownership changed significantly. Children were more often reported to wear life vests if a parent knew of the campaign, was confident fitting the vest, was younger than 40 years, felt the child could not swim well, and owned a life vest for the child.

Conclusions-A community-wide drowning prevention campaign resulted in a significant, although modest, increase in reported life vest use and ownership among children.

(Injury Prevention 1999;5:109-113)
\end{abstract}

Children's Hospital and Regional Medical

Center, Seattle

E Bennett

University of Washington, Seattle: Department of

Epidemiology

P Cummings

Department of Pediatrics

L Quan

Department of Family and Child Nursing F M Lewis

Correspondence to: Elizabeth Bennett, Health Education, CM-09, Children's Hospital and Regional Medical Center, 4800 Sandpoint Way NE, Seattle, WA 98105, USA. In 1992, drowning was the second leading cause of injury death for children under 15 years of age in the United States. ${ }^{1}$ It has also been one of the leading causes of injury death among children in Japan, South Africa, Britain, Sweden, Canada, and Australia. ${ }^{2-7}$ From 1990 through 1994, there were 5344 drownings among children in the United States in this age group: 1.9/100 000 person years. For children less than 5 years old, the rate was 2.9/100 $000{ }^{8}$

In King County and Washington State, swimming pools were the leading site of drowning among children less than 5 years. Natural bodies of water (lakes, rivers, and ponds) were the second most common location and bath tubs the third most common. For older children, natural bodies of water were the most common sites for drowning. Swimming, wading, using inner tubing, and playing on docks or on lake and river edges were the leading activities that preceded drowning. ${ }^{9}{ }^{10}$ Similar results were found in an analysis of child drowning and near-drowning in Britain. ${ }^{4}$

Other than pool fencing, few drowning prevention interventions have been evaluated. ${ }^{11}$ Community based programs targeting children have focused on supervision, pool fencing, learning cardiopulmonary resuscitation, learning to swim, and water safety training. ${ }^{12-17}$ The use of life vests (also known as personal flotation devices, PFDs, or life jackets) has been suggested as a method of reducing drowning mortality and morbidity in children when boating or playing beside streams, rivers, or lakes. ${ }^{118-20}$ In Sweden, increasing the availability of life vests at water sites was one component of a program that decreased drowning among children. ${ }^{5}$

This report describes a regional drowning prevention campaign and evaluates its effect. The campaign focused on life vest use as the primary prevention method because of its potential effectiveness at a variety of sites for children of all ages.

\section{Methods}

PROGRAM METHODS

The drowning prevention campaign, called "Stay on Top of It", was established by Children's Hospital and Regional Medical Center in March 1992. It was designed to run through three summer seasons to September 1994 in King County, Washington, which contains the city of Seattle and had 1507305 residents in $1990 .^{21}$ The two primary objectives were to increase life vest use among 1-14 year old children on boats, docks, at beaches, and swimming pools, and to increase general water safety awareness. A secondary objective was to increase life vest ownership.

Social marketing provided the overall structure for the surveys, planning and tracking, target groups, and the use of multimedia channels. ${ }^{22}$ Survey questions included predisposing, enabling, and reinforcing factors from the PRECEDE model. ${ }^{23}$ Elements of social cognitive theory and protection motivation theory guided message development, self efficacy, skill practice, reinforcement, and role modeling. ${ }^{24-26}$ Program elements were also guided by survey results, drowning prevention literature, and the Seattle bicycle helmet campaign. $^{27}$

The primary target of the interventions was children up to 9 years with some elements extending to children up to 14 years. Specific messages and tactics depended on the child's age and water site. For example, life vest use in 

Table 1 Drowning prevention campaign elements,

\begin{tabular}{|c|c|c|c|}
\hline & 1992 & 1993 & 1994 \\
\hline \multicolumn{4}{|l|}{ Media and publicity } \\
\hline Press conference & $\mathrm{x}$ & $\mathrm{x}$ & \\
\hline Television news and public service & $\mathrm{x}$ & $\mathrm{x}$ & $\mathrm{x}$ \\
\hline $\begin{array}{l}\text { Newpaper news and public } \\
\text { service }\end{array}$ & $\mathrm{x}$ & $\mathrm{x}$ & $\mathrm{x}$ \\
\hline Radio news and public service & $\mathrm{x}$ & $\mathrm{x}$ & $\mathrm{x}$ \\
\hline Bus advertisements & $\mathrm{x}$ & $\mathrm{x}$ & \\
\hline Banners at water activity sites & $\mathrm{x}$ & $\mathrm{x}$ & $\mathrm{x}$ \\
\hline Advertisements on grocery bags & $\mathrm{x}$ & $\mathrm{x}$ & \\
\hline $\begin{array}{l}\text { Hotline number to order } \\
\text { materials }\end{array}$ & $\mathrm{x}$ & $\mathrm{x}$ & $\mathrm{x}$ \\
\hline \multicolumn{4}{|l|}{ Printed education materials } \\
\hline Parent booklet and fact sheets & $\mathrm{x}$ & $\mathrm{x}$ & $\mathrm{x}$ \\
\hline Activity booklet for children & & $\mathrm{x}$ & $\mathrm{x}$ \\
\hline Ten sports hero trading cards & & $\mathrm{x}$ & $\mathrm{x}$ \\
\hline Hospital publications & $\mathrm{x}$ & $\mathrm{x}$ & $\mathrm{x}$ \\
\hline Day camp activity booklet & & & $\mathrm{x}$ \\
\hline Tip sheet for boaters & & & $\mathrm{x}$ \\
\hline Targeted mailings & $\mathrm{x}$ & $\mathrm{x}$ & $\mathrm{x}$ \\
\hline \multicolumn{4}{|l|}{ Promotions/special events } \\
\hline Staffed booths at events & $\mathrm{x}$ & $\mathrm{x}$ & $\mathrm{x}$ \\
\hline Display tank of dolls in vests & $\mathrm{x}$ & $\mathrm{x}$ & $\mathrm{x}$ \\
\hline Interactive board with vests & & $\mathrm{x}$ & $\mathrm{x}$ \\
\hline Rubber raft with life vests & $\mathrm{x}$ & $\mathrm{x}$ & $\mathrm{x}$ \\
\hline Plastic take home bags & & $\mathrm{x}$ & $\mathrm{x}$ \\
\hline Stickers & $\mathrm{x}$ & $\mathrm{x}$ & $\mathrm{x}$ \\
\hline Ice cream coupons for vest use & & & $\mathrm{x}$ \\
\hline Raffles & $\mathrm{x}$ & $\mathrm{x}$ & $\mathrm{x}$ \\
\hline April Pools Day sponsorship & $\mathrm{x}$ & $\mathrm{x}$ & $\mathrm{x}$ \\
\hline \multicolumn{4}{|l|}{ Life vest programs } \\
\hline Loan programs & $\mathrm{x}$ & $\mathrm{x}$ & $\mathrm{x}$ \\
\hline Discount coupons & $\mathrm{x}$ & $\mathrm{x}$ & $\mathrm{x}$ \\
\hline Retail displays & $\mathrm{x}$ & $\mathrm{x}$ & $\mathrm{x}$ \\
\hline Bulk buy for public pools & & & $\mathrm{x}$ \\
\hline
\end{tabular}

a boat was recommended for all children, use in a pool was targeted towards younger children.

To increase general water safety and life vest awareness, the following were developed and implemented: coalition support and involvement, community partnerships, sponsor relationships, news reporting and public service advertising, educational materials, interactive displays, and programs to increase life vest availability (table 1). Many of the campaign elements were disseminated through organizations and care providers who had direct contact with families. For example, pediatricians provided information at well child visits and pools had life vests to borrow during family swim times.

EVALUATION METHODS

A process evaluation was conducted by tracking program activities, media response, number of individuals participating in events, and life vest loan program use.

To assess program impact, four telephone surveys were conducted with parents. The surveys (1) determined awareness of the campaign and the primary message about life vest use; (2) assessed changes in life vest use for children; and (3) assessed changes in ownership of life vests for children.

Data regarding Washington drownings that were not in bathtubs were obtained, along with population estimates, from compressed mortality files of the National Center for Health Statistics. ${ }^{8}$ These data were analyzed using Poisson regression. ${ }^{28}$

SURVEY INSTRUMENT AND SAMPLE

To determine if parental knowledge, attitudes, and reported use and ownership of life vests by children changed as a result of exposure to the campaign, four telephone surveys were conducted: a baseline (pre-campaign) survey in March 1992, two tracking surveys in September 1992 and 1993, and a post-campaign survey in September 1994. The baseline survey assessed behaviors, attitudes, and potential strategies. The tracking surveys measured awareness, and the post-campaign survey assessed awareness, behaviors, attitudes, and factors associated with life vest use. Telephone surveys were conducted by market research firms and targeted residents of King County, Washington who had children up to 9 or 14 years old living at home, depending on the survey.

Telephone numbers were selected randomly from purchased lists of families likely to have children. The pre-campaign survey used purchased lists from sources such as warranty cards and subscriptions. The tracking and post-campaign surveys used white page phone listings to improve the range of respondents. An estimated $2 \%$ of King County residents were not included in the telephone samples because they did not have telephones. ${ }^{21}$

Screening questions were used to select parents who were responsible for the day-to-day care of their children, had children living at home with them, and reported that one or more of their children had ever gone boating, or went to swimming pools, or to beaches, lakes, rivers, or docks. There were no survey exclusion criteria based on attributes such as income or zip code.

Parents were asked about their education, income, and age. Responses about behavior were coded using a five point scale from "always" to "never". Questions about attitudes were coded using a four point scale; from "strongly agree" to "strongly disagree". During the analysis, questions with four point scales were collapsed into two responses, agree or disagree. The responses about life vest use were divided by use of life vest up to and including half the time or more than half the time. Responses were analyzed by randomly selecting one child from each family.

DATA ANALYSIS

To test the significance of differences in proportions $\chi^{2}$ statistics were used and $\mathrm{p}$ values were based on two sided tests. For some questions, the absolute differences in response proportions was calculated with the $95 \%$ confidence interval (CI). ${ }^{29} 30$ The strength of association between reported life vest use and other factors was expressed as an odds ratio, and logistic regression was used to control for potential confounders. ${ }^{28}$

\section{Results}

\section{PROCESS EVALUATION}

Publicity included coverage on television, radio, newspapers, press conferences, advertisements on buses, and seven television public service announcements that aired an estimated 3000 times. A telephone hotline received an average of 150 calls per month from May to 
Table 2 Telephone sampling data and response rates for drowning prevention campaign surveys

\begin{tabular}{llll}
\hline & $\begin{array}{l}\text { Pre-campaign } \\
\text { (March 1992) }\end{array}$ & $\begin{array}{l}\text { Tracking surveys } \\
\text { (September 1992, }\end{array}$ & $\begin{array}{c}\text { Post-campaign } \\
\text { (September 1994) }\end{array}$ \\
\hline Total phone contacts & 697 & $\star$ & 1859 \\
Refusals & 224 & $\star$ & 859 \\
Not qualified & 141 & $\star$ & 520 \\
Completed interviews & 332 & 200 & 480 \\
Response proportion $\dagger$ & $60 \%$ & & $36 \%$ \\
Interviewed families by age of child (years) $\neq$ & 100 & 176 \\
$1-4$ & 150 & 100 & 273 \\
$5-9$ & 181 & na & 254 \\
$10-14$ & 171 & & \\
\hline
\end{tabular}

$\star$ Data not available.

$\dagger$ Response proportion $=$ (completed interviews) $/$ (qualified contacts).

$\ddagger$ Some families are in the table more than once because they had children in more than one age category.

September and a children's radio station promotion resulted in over 2000 calls from families.

Written materials included a booklet for parents, five fact sheets, 10 sports hero trading cards in English and Spanish and an activity booklet for children. A mail-in card with the activity booklet asked for information on behaviors and enabled a child to receive a set of trading cards. Over $10 \%$ (10 000) of the cards were returned. Interactive displays at special events reached an estimated 5000 people each year, providing opportunities to learn about life vests.

To increase ownership, $\$ 5.00$ discount coupons for children's life vests were distributed. Although coupon redemption was not tracked, the life vest manufacturer showed a $25 \%$ to $50 \%$ increase in children's life vest sales in Washington State each year of the campaign.

To increase life vest use at beaches, docks, and swimming pools, loan programs were implemented. The most common age of children borrowing life vests was 3-5 years. On average, 500 loans were made at 13 sites during the 10 week season with lifeguards, for a total of 6500 loans per year (there were no loan programs before the campaign).

\section{IMPACT EVALUATION}

The pre-campaign survey completed 332 interviews, 200 families were interviewed during each of the tracking surveys, and 480 families completed the post-campaign survey. Of families who were contacted and met the screening criteria, the pre-campaign survey had a $60 \%$ response rate and the post-campaign survey had a $36 \%$ response rate (table 2 ).

The parents surveyed in the pre-campaign and post-campaign period were similar in the proportion who were younger than 40 years $(56 \%$ v 53\%); who were college graduates
( $50 \%$ v 52\%); who had more than one child ( $45 \%$ v 46\%); and who had reported annual incomes equal to or over $\$ 30000(91 \%$ v $88 \%$ ). In the 1990 United States census, 80\% of all King County families reported having an estimated annual income to be equal to or over $\$ 25000 .^{21}$

\section{AWARENESS OF CAMPAIGN}

Increasing proportions of parents reported awareness of the campaign over time in both prompted and unprompted responses. In the 1992 and 1993 tracking surveys, an average of $38 \%$ of parents said they were aware of the campaign; in 1994 this increased to $50 \%$.

Respondents who recalled the campaign, without prompting, reported three campaign messages most frequently. "Wear a life vest" recall increased from $31 \%$ to $47 \%$ from the first to third year, a change of $+16 \%$ (95\% CI $0 \%$ to $+32 \%)$. "Supervise children around water" was the second most frequently mentioned message, increasing from $26 \%$ to $44 \%$, a change of $+18 \%(95 \% \mathrm{CI}+2 \%$ to $+34 \%)$. The third most frequently mentioned message, "learn guidelines for water safety" increased from $7 \%$ to $28 \%$, a $+21 \%$ change $(95 \%$ CI $+10 \%$ to $+32 \%)$.

Respondents were asked whether they recalled seeing or hearing information about the campaign on specific products like busboards or education materials. The most frequently recalled elements were: television news and public service announcements, the guide for parents, and the activity booklet for children.

USE OF LIFE VESTS

Parents were asked how often their child wore a life vest in three types of settings: (1) at a beach, lake, river, or dock; (2) in or around a swimming pool; and (3) on boats or rafts. Reported use in the first two settings for all child age groups increased significantly, from $20 \%$ to $29 \%$ ( $+9 \%, 95 \%$ CI $+3 \%$ to $+15 \%$, $\mathrm{p}<0.01$ ) (table 3). Reported use was 34\% among those who said they were aware of the campaign.

Using 1990 United States census data for families with children younger than 18 years old, these results suggest that about 13000 families increased their life vest use, at an estimated campaign cost of $\$ 7.00$ per family. ${ }^{21}$

Reported life vest use on boats showed little change, however, because of a ceiling effect. Among children who spent time in boats, use of life vests more than half the time was over $90 \%$ at the start.

The odds for reported use of a life vest by a child at beaches, pools, or docks were greater

Table 3 Comparison of life vest use and ownership by children age 1-14 years before and after drowning prevention campaign

\begin{tabular}{|c|c|c|c|c|c|c|c|c|c|}
\hline & \multirow{2}{*}{$\begin{array}{l}\text { No of families } \\
\text { interviewed }\end{array}$} & \multicolumn{4}{|c|}{$\begin{array}{l}\text { Life vest use by child on docks, at beaches, or pools more than } \\
\text { half the time }\end{array}$} & \multicolumn{4}{|c|}{ Own a life vest for child } \\
\hline & & No $(\%)$ & $\%$ Change* & $95 \% C I$ & $p$ Value & No $(\%)$ & $\%$ Change* & $95 \% C I$ & $p$ Value \\
\hline Pre-campaign & 332 & $65(20)$ & & & & $230(69)$ & & & \\
\hline \multicolumn{10}{|l|}{ Post-campaign } \\
\hline Aware of campaign & 240 & $81(34)$ & $+14 \%$ & $+7 \%$ to $+22 \%$ & 0.001 & $191(80)$ & $+11 \%$ & $+3 \%$ to $+17 \%$ & 0.006 \\
\hline Unaware of campaign & 240 & $57(24)$ & $+4 \%$ & $-3 \%$ to $+11 \%$ & 0.2 & $170(71)$ & $+2 \%$ & $-6 \%$ to $+9 \%$ & 0.7 \\
\hline Total & 480 & $138(29)$ & $+9 \%$ & $+3 \%$ to $+15 \%$ & 0.003 & $361(75)$ & $+6 \%$ & $0 \%$ to $+12 \%$ & 0.06 \\
\hline
\end{tabular}

${ }^{\star}$ Difference in proportions before and after campaign. Positive numbers mean more life vest use or ownership after the campaign. 
Table 4 Predictors of life vest use by children $(n=480)$

\begin{tabular}{|c|c|c|c|c|c|}
\hline & $\begin{array}{l}\text { No (\%) of parents with } \\
\text { predictive factor who report child } \\
\text { use of life vests }>\text { half the time }\end{array}$ & $\begin{array}{l}\text { No (\%) of parents with } \\
\text { predictive factor who report child } \\
\text { use of life vests } \leqslant \text { half the time }\end{array}$ & $p$ Value & Odds ratio & $95 \% C I$ \\
\hline Child vest ownership & $119(86)$ & $242(71)$ & $<0.001$ & 2.6 & 1.5 to 4.4 \\
\hline Parental age $<40$ years & $93(69)$ & $164(49)$ & $<0.001$ & 2.3 & 1.5 to 3.6 \\
\hline Confident fitting a life vest & $130(94)$ & $281(83)$ & 0.003 & 3.2 & 1.5 to 7.0 \\
\hline Child does not swim well & $87(63)$ & $177(52)$ & 0.03 & 1.6 & 1.1 to 2.4 \\
\hline Parent recalls campaign & $81(59)$ & $159(47)$ & 0.02 & 1.6 & 1.1 to 2.5 \\
\hline Use of life vest by parents who boat & $49(58)$ & $105(48)$ & 0.1 & 1.5 & 0.9 to 2.4 \\
\hline Perceived susceptability of child to drowning & $92(67)$ & $199(59)$ & 0.1 & 1.4 & 0.9 to 2.1 \\
\hline Not a college graduate & $72(53)$ & $153(45)$ & 0.2 & 1.3 & 0.9 to 2.0 \\
\hline Reported income $<\$ 30$ 000/year & $17(15)$ & $34(12)$ & 0.4 & 1.3 & 0.7 to 2.6 \\
\hline Believe in efficacy of life vest & $137(99)$ & $338(99)$ & 1.0 & 1.2 & 0.1 to 64.3 \\
\hline
\end{tabular}

among those surveyed after the campaign compared with the baseline survey: odds ratio 1.6 (95\% CI 1.1 to 2.5). Logistic regression was used to assess confounding factors, including child vest ownership, parent age, parent's confidence fitting a vest, child's swimming ability, parent use of vest, perceived susceptibility to drowning, parent's education and income, and perceived efficacy of vest. Adjustments for these factors did not appreciably change the odds ratio for the association between use and the campaign.

Reported ownership of vests for all age groups increased from $69 \%$ in the precampaign survey to $75 \%$ in the post-campaign survey. Among those aware of the campaign, ownership increased to $80 \%$ (table 3 ).

To determine predictors of use, campaign recall as well as the above factors were examined. In univariate analyses, life vest use for children on docks, at beaches or swimming pools was more likely if: the child owned a vest; the parent recalled the campaign; the parent felt confident fitting a vest; the child did not swim well; or if the parent was less than 40 years old (table 4). Parent age was probably associated with life vest use because younger children were more likely to wear life vests on beaches, docks, and at swimming pools, and were more likely to have younger parents. When the above four variables were in the same logistic model the odds ratios were only minimally changed and all were statistically significant except swimming ability. Although almost all parents reported their belief in the efficacy of life vests, it was not a predictor of use.

The campaign's impact on childhood drowning is undetermined and the total numbers of drownings are small, making statistical tests difficult. However, during the three years before the campaign, 12 children aged 1-14 years drowned in King County, compared with eight deaths in the campaign years. For the rest of the state, not targeted by the campaign, 32 children drowned during the three years before the campaign and 39 drowned in the campaign years. The rate ratio for drowning mortality during the campaign, compared with what it might have been if King County had followed the trend of the rest of the state, was 0.58 (95\% CI 0.21 to 1.58 ).

\section{Discussion}

A three year drowning prevention campaign was associated with a significant increase in reported use of life vests at beaches, docks, and pools among children age 1-14 years. Life vest ownership by children increased significantly among families aware of the campaign. Children were more often reported to wear a life vest if a parent knew of the campaign, was comfortable fitting a vest, felt the child could not swim well, if the child was younger, and if the child owned a life vest.

The drowning prevention campaign incorporated many elements of the successful Seattle bike helmet campaign: for example working through a coalition, a narrow focus (life vest use), specific age group, use of mass media, and coupons to reduce the cost. ${ }^{27}$ However, the need to wear a life vest is a more complex message to convey than the need to wear a bike helmet. While bike helmets are recommended for all ages whenever a bicycle is used, life vest use depends on water site, water activity, and the age and abilities of the child. Furthermore, whereas the bike helmet campaign had a single message, this campaign incorporated the importance of adult supervision because life vests do not replace supervision in preventing childhood drowning. ${ }^{31}$

There are limitations to our results. Some of the increase in use may be attributable to other educational efforts. However, parents who were unaware of the campaign reported little increase in life vest use.

Although families in the study were demographically similar to all King County families with children, we did not use a random digit dialing method, and this could have biased our results. The proportion of interviewed families with high incomes was greater than for all King County families, so our findings may not apply to low income families.

Our study may have been biased because self reported information was used and people tend to exaggerate positive behaviors. ${ }^{32-34}$ However, while people may exaggerate their use of life vests, the differences in use before and after the campaign may still accurately reflect changes in use. It is possible that people aware of the prevention campaign were more likely to exaggerate use of life vests.

Finally, the pre-campaign survey used a different sampling method than the tracking and post-campaign surveys. It is possible that the post-campaign survey population was more likely to use life vests than the pre-campaign population. The proportion of completed questionnaires to total calls made, $60 \%$ in the pre-campaign survey and $36 \%$ in the post- 
campaign survey, may be due to the different phone lists used. The baseline population was derived from subscription and warranty type lists. These parents may be more willing to respond to questionnaires. Also, the postcampaign survey was almost twice as long as the baseline survey, which may have resulted in the higher per cent of initial refusals. However, the populations sampled in the pre-campaign and post-campaign surveys were similar in age, income, education, and number of children. In addition, within the post-campaign survey, use and ownership of life vests differed between respondents who reported being aware of the campaign and those who did not indicate campaign awareness.

\section{Implications for prevention}

We found a significant, although modest, increase in reported life vest use and ownership among children age 1-14 years associated with a three year drowning prevention campaign. Programs targeting life vest use may want to consider multiple strategies that include targeted audiences and messages by water site, increasing parent confidence in fitting a life vest and life vest availability through discount and loan programs. A comprehensive, community based campaign, with a focus on increasing the use of life vests, may be one method of decreasing drowning among children.

This research was supported by Children's Hospital and Regional Medical Center in Seattle, Washington. We wish to thank the Seattle-King County Drowning Prevention Coalition, tion, Children's Hospital, and all our other partners for their tion, Children's Hospith
help with this project.

1 Baker SP, Fingerhut LA, Higgins L, et al. Injury to children and teenagers state by state mortality facts. Baltimore, MD: 2 Mizuta R, Fujita H, Osamura T, et al. Childhood drownings Mizuta R, Fujita H, Osamura T, et al. Childhood drownings and near-

3 Kibel SM, Joubert G, Bradshaw D. Injury-related mortality in South African children. S Afr Med F 1990;78:398-403.

$4 \mathrm{Kemp} \mathrm{A}$, Sibert JR. Drowning and near drowning in children in the United Kingdom: lessons for prevention. BMF 1992;304:1143-6.

5 Bergman AB, Rivara FP. Sweden's experience in reducing childhood injuries. Pediatrics 1991;88:69-74.

6 Canadian Red Cross Society. Drownings among 1 to 4 year old children in Canada. A high risk group for water related fatalities. Ottawa: Canadian Red Cross Society of Canada, 1994.

7 Cass DT, Ross FI, Grattan-Smith TM. Child drownings: a changing pattern. Med F Aust 1991;154:163-5.
8 Centers for Disease Control and Prevention. CDC Wonder Website. Available at http://wonder.cdc.gov.

9 Rowland J. Drowning in Washington State. Olympia, WA: Washington State Injury Prevention Program, Washington State Department of Health, 1991.

10 Quan L, Gore EF, Wentz K, et al. Ten-year study of pediatric drownings and near drownings in King County, Washington: lessons in injury prevention. Pediatrics 1989; 83:1035-40.

11 American Academy of Pediatrics. Committee on Injury and Poison Prevention. Drowning in infants, children and adolescents. Pediatrics 1993;92:292-4.

12 Frisby ML, Hill JH. A community's response to childhood drownings. Crit Care Clin 1991;3:373-9.

13 Jensen LR, Williams SD, Thurman DJ, et al. Submersion injuries in children younger than five years in urban Utah. West f Med 1992;157:641-5.

14 Liller KD, Kent EB, Arcari C, et al. Risk factors for drowning and near-drowning among children in Hillsborough County Florida. Public Health Rep 1993;108:346-53.

15 Coffman SP. Parent education for drowning prevention. $\mathcal{F}$ Pediatr Health Care 1991;5:141-6.

16 Asher KN, Rivara FP, Felix D, et al. Water safety training as a potential means of reducing risk of young children's drowning. Inj Prev 1995;1:228-33.

17 Royal Life Saving Society Canada. Water smart campaign. Ontario, Canada: Royal Life Saving Society, 1992.

18 National Committee for Injury Prevention and Control. Injury prevention: meeting the challenge. New York, NY: Oxford University Press, 1989: 163-75.

19 Seattle King County Department of Public Health. Data summaries. Seattle, WA: Seattle King County Drowning Prevention Coalition, 1991

20 Washington State Department of Health. Public health improvement plan. Olympia, WA: Washington State Department of Health, 1994: 83-196.

21 US Bureau of the Census. 1990 Census of population, general population characteristics. Washington, DC: US Government Printing Office, 1992.

22 Kotler P, Andreasen AR. Strategic marketing for nonprofit organizations. Englewood Cliffs, NJ: Prentice-Hall, Simon and Schuster, 1987.

23 Green LW, Kreuter MW. Health promotion planning: an educational and environmental approach. Mountain View, CA: cational and environmental

24 Bandura A. Social learning theory. Englewood Cliffs, NJ: Prentice Hall, 1986

25 Rogers RW. A protection motivation theory of fear appeals and attitude change. F Psychol 1975; 91:93-114.

26 O'Leary A. Self efficacy and health. Behav Res Ther 1985;23:437-51.

27 Bergman AB, Rivara FP, Richards DD, et al. The Seattle children's bicycle helmet campaign. Am f Dis Child 1990;144:727-31.

28 Breslow NE, Day NE. The analysis of case-control studies. Statistical methods in cancer research. Vol 1. Lyon, France: International Agency for Research on Cancer, 1980: 190246.

29 Gardner MJ, Altman DG, eds. Statistics with confidence. London: BMJ Publishing Group, 1989.

30 Gardner MJ, Gardner SB, Winter PD. Confidence interval analysis (CIA) software. Version 1.0. London: BMJ Publishing Group, 1989. (IARC Scientific Publication No 32.)

31 Brill JE. Dispelling the myth of the drownproof child. Contemporary Pediatrics 1987; June:30-43.

32 Pless IB, Arsenault L. The role of health education in the prevention of injuries to children. Fournal of Social Issues 1987;43:87-103.

33 DiGuiseppi CG, Rivara FP, Koepsell TD. Attitudes toward bicycle helmet ownership and use by school-age children. Am f Dis Child 1990;144:83-6.

34 Mawson AR, Biundo JJ. Contrasting beliefs and actions of drivers regarding seat belts: a study in New Orleans. $\mathcal{F}$ Trauma 1985;25:433-6. 